\title{
The Use of Computer Based Testing Method for the Conduct of Examinations at the University of Ilorin
}

\author{
Dr. (Mrs.) A.T. Alabi \\ Senior Lecturer, Department of Educational Management, Faculty of Education, \\ University of Ilorin, Ilorin, Kwara State, Nigeria \\ E-mail: alabiafusat@yahoo.com
}

Dr. A. O. Issa

Senior Lecturer \& Head, Department of Library and Information Science,

Faculty of Communication and Information Sciences, University of Ilorin, Ilorin, Kwara State,

Nigeria

E-mail: abdulwahab.issa@yahoo.com

R. A. Oyekunle (Mrs.)

Assistant Lecturer, Department of Information and Communication Science,

Faculty of Communication and Information Sciences, University of Ilorin, Ilorin, Kwara State,

Nigeria

E-mail: ummusumayya1@yahoo.com

Accepted: April 5, 2012 Published: May 06, 2012

Doi:10.5296/ijld.v2i3.1775 URL: http://dx.doi.org/10.5296/ijld.v2i3.1775

\begin{abstract}
This paper presents an overview of the application of Information and Communication Technology in the conduct of post-UTME and other examinations at the University of Ilorin. It provides a brief historical background to the practice at the University, dating back to 2005 when it started by adopting the Pen-and-Paper Testing up to the present practice, using the Computer-Based Testing method. The paper underscored the challenges associated with the former practice, thus justifying the introduction of the latter, thereby justifying it. In conclusion, this paper advocates the widespread adoption of CBT method for the conduct of
\end{abstract}


not just the post-UTME examinations, but also other University-based examinations with large population of students in Nigerian Universities owing to the success story of the University of Ilorin.

\section{Introduction}

Information and Communication Technology (ICT) has become, within a very short time, one of the basic building blocks of modern society. Many countries now regard understanding it and mastering its basic skills and concepts as very crucial in education. This is because it adds value to the processes of learning and to the organization and administration of learning institutions. It encompasses different types of technologies, which are utilized for capturing, processing and transmitting data and information, using computer facilities. It is an umbrella term that includes communication device or application, encompassing radio, television, cellular phones, computers, network, hardware and software, satellite systems and so on, as well as the various services and applications associated with them (Kumar, 2006).

Thus, ICT focuses specifically on the application of these new technologies in an educational context and environment, and serves as a tool for supporting the various components of education. Such components include, among others, teaching and learning, resources management (human, material, financial resources) and admission and examination processes also known as learning assessment. One specific form of ICT for assessment is the Computer-Based Testing (CBT), also known as Computer-Based Assessment or e-exam. It is a method of administering tests in which the responses are electronically recorded, assessed, or both. It is commonly available for several admissions tests throughout the developed countries (Wikipedia, 2012). This method of testing is important because it can measure different skills or sets of knowledge in order to provide new and better information about individuals' abilities. Colleges and universities receive CBT results more quickly than those from paper-based test, and they can make their admissions decisions more quickly. Individuals can take a CBT even with minimal or no previous computer experience; since; instructions provided in a basic computer tutorial before the test will provide the experience needed to take the test using a mouse. One may spend much time on the tutorial to ensure comfortability with the computer and with the test before the official timed examination.

The two types of CBTs are linear and adaptive, whereby a linear test is a full-length examination in which the computer selects different questions for individuals without considering their performance level. It consists of a full range of test questions-from easiest to most difficult-but not always in that order. The linear test is scored in the same way as a paper-based test. A computer adaptive test is one in which the computer selects the range of questions based on individuals' performance level. These questions are taken from a very large pool of possible questions categorized by content and difficulty. When you take a paper-based test, you will find that you are asked to answer questions ranging from easy to hard. In a computer-based adaptive test, each test-taker receives questions that are at the right level of difficulty for his or her ability. These tests begin with a question that is of medium level of difficulty for most test takers. After each question is answered, the computer uses the answer and all previous answers to determine which question will be answered next. The next question is one that best follows the previous performance. This means that different test takers-even in 
the same room on the same day-will receive different questions. Since adaptive test questions are selected according to performance on previous questions, less time is spent than on a paper-based test on questions that are either too easy or too hard. Usually, one cannot skip ahead or go back as is possible with the paper-based examination.

Friedrich (2008) noted that CBT enables educators and trainers to author, schedule, deliver and report on surveys, quizzes, tests and exams. It could be a stand-alone system or a part of a virtual learning environment, possibly accessed via the World Wide Web. In addition to the examination itself, CBT takes care of other related activities that interact with the assessment such as test administration, setting questions and automated marking. Computers are used by candidates to conduct their examinations online, usually in the form of multiple choice questions, submit and get immediate results.

Examinations, in this context, refer to tests which aim to determine the ability of a student or a prospective candidate into an institution of learning; which are usually written tests, sometimes with practical components. The Post-JAMB Screening Examination is a competitive examination, in which candidates compete for a limited number of admission places into the different academic programmes of the universities. As for Harding and Raikes (2000), new styles of learning have an exciting image in the world of ICT -led innovations, but assessment usually fails to raise enthusiasm. Assessment needs to be taken as a very vital component of the educational process because one of the challenges facing educational institutions today is the conduct of examinations resulting in valid and reliable scores.

\section{Review of Related Literature}

There have been research aimed at establishing the equivalence of CBTs with PPTs especially when computers gave exactly the same tests as those given in paper-and-pencil formats. It therefore became imperative to define score equivalence, which was readily found in the American Psychological Association's Guidelines for Computer-Based Tests and Interpretations published in 1986. The guidelines define the score equivalent of computerised tests and conventional paper-and-pencil test in two ways. First, that the rank order of scores of individuals tested in alternative modes closely appropriate each other; and second, that the means, dispersions and shapes of the score distributions approximate the same by re-scaling the scores from the computer tests versions (APA, 1986). The guidelines also require that any effects due to computer administration be either eliminated or accounted for in interpreting scores.

On their part, Olsen, Maynes, Slawson \& Ho (1986) compared paper-administered, computer-administered, and computer-adaptive tests by giving third- and sixth-grade students mathematics applications achievement tests. They found no significant differences between paper-administered and computer-administered tests, and equivalences among the three test administrations in terms of score rank order, means, dispersions, and distribution shapes. Envisage International Cooperation (2010) pointed out that CBT may affect test scores and consequently their equivalence with PPT, and that test with reading passages may be more difficult when given on computers

Thus, Bugbee (1996) concluded that the use of computers really affects testing; notwithstanding that CBT and PPT can be equivalent especially when the test developers take 
responsibility by showing how the equivalent can come by. He stated further that the barriers to the use of CBT are inadequate test preparation and failure to grasp the unique requirements for implementing and maintaining them; emphasizing that such factors as the design, development, administration and user characteristics needed to be considered in using CBT. Schenkman, Fukuda \& Persson (1999) identified one of the numerous variables that impact on student's performance when questions are presented on a computer to be the quality of the monitor. On the impact of CBT on student attitudes and behavior, Butler (2003) confirmed the association between a moderate number of tests and better student attitudes; especially that his respondents were found to be generally more positive toward the proctored, CBT facility than toward in-class, pencil and paper testing.

Similarly, Donn (1991) found that the mean achievement score was significantly higher for the computer-based group in a study of the effects of a CBT on the achievement and test anxiety exploring the relationship between computer anxiety and computer experience and assessing the affective impact of computerized testing on students. There were neither a significant difference in text anxiety between the groups, on the one hand nor a significant relationship between their computer experience and anxiety owing to taking the CBT. The conclusion reached by the study that if computerized test-taking tasks are kept simple, even test-takers with minimal computer experience may not be disadvantaged, was informed by respondents' positive reactions toward CBT generally.

Research outcomes have thus supported the fact that when students are motivated and testing conditions are equivalent, there are no differences between the scores obtained via computer-based or paper-pencil tests (Lynch, 1997 \& Marson, Patry, and Berstein, 2001). Other research results suggest that although students may be disadvantagged, at the initial stage, which may account for why Wingenbach (2000) found no significant associations between academic achievement and students' attitudes towards computers, computing anxiety levels, attitudes towards electronic examinations, or gender by the introduction of CBT, such a setback was temporary (Ricketts and Wilks, 2002).

Thus the initial low academic achievement in CBT, occasioned by such detrimental effects as computing and/or test anxiety soon disappeared as later CBT examinations produced impressive academic achievement for many respondents. The most recent endorsement of this viewpoint came from Tella and Bashorun (2012) in a study whose results demonstrated that the University of Ilorin students, their respondents, have positive attitude towards CBT as more than half of them indicated preference for CBT over PPT in addition to establishing a strong perception that CBT increase respondents' performance in learning. Scalise. \& Gifford (2006)

\section{Post-JAMB Screening Exercise in Nigeria}

The Joint Admission and Matriculation Board (JAMB), established by Decree No 2 of 1978 (amended by Section 5 of Decree 33 of 1989) was Nigeria's official entrance examination board for candidates seeking admission to the nation's universities. Before then, the nation's existing universities conducted what they referred to as their 'concessional' entrance examinations for prospective students. The process of administering the examination, on the part of the candidates, was not only time-wasting, but was untidy and uncoordinated, especially with the increasing number of universities as well as prospective candidates. 
Some of its functions are to generally control the matriculation examination for admissions into all universities, polytechnics and colleges of education in Nigeria; to appoint examiners, moderators, invigilators, members of the subject panels and committees and other persons with respect to Matriculation Examinations and any other matters incidental thereto or connected therewith and to place suitably qualified candidates in the tertiary institutions. The Board also undertakes the conduct of the Universities Matriculation Examination (UME) and sends the results to universities chosen by the candidates, so that each university selects and recommends candidates to JAMB for admission; as well as allow each university to conduct tests/interview termed screening for candidates before selecting those to recommend; conduct similar entrance examination for candidates applying to Polytechnics and College of Education (Jekayinfa, 2008).

The Nigerian university system began the post-JAMB Screening Examinations in 2005 as a way of validating the scores obtained by candidates in the University Matriculation Examinations (UME) organized by the Joint Admissions and Matriculation Board (JAMB). Prior to this time, there had been a growing concern about the conduct, authenticity and reliability of the UME for the purpose of selecting qualified prospective candidates into Nigerian universities. There was also the insinuation from many quarters as to the likely compromise of the examination body, which led many to conclude that it does not have the required capacity to discharge its responsibility any longer.

It was in response to the above situation that the University of Ilorin became one of the first to start organizing post-JAMB test as far back as 2005, using the Pen-and Paper Testing (PPT) format, up till 2007. As the 2007/2008 academic session of the University ended May 2008 , prospective candidates for admission into the university for 2008/2009 academic session were notified that the senate of the university has decided that admission exercise would be by CBT. However, the PPT presented many problems some of which include:

1. Tedious processes as the examination was conducted at various and distant centres simultaneously and marked manually.

2. High risks of accidents during travels by both the university staff involved and the prospective students for the paper examination.

3. Cost of conduct of the examination on the part of the university including honoraria for invigilators, coordinators, markers collators and other allied staff.

4. Subjective scoring and plausible manipulation of results.

5. Late release of results and missing grades.

6. Bank draft method of payment by candidates riddled by

fraud, loss of money, stress and trauma.

Thus, observation has revealed that the conduct of post-JAMB screening examinations and other examinations with a large population of students in the university, using the PPT method, was beset with numerous limitations culminating in invalid and unreliable outcomes. To overcome these challenges and forge ahead in an increasing ICT-propelled society, the University of Ilorin commenced the CBT method for its post-JAMB screening exercise in 2008. Since assessment of learning activities is a very important aspect of the education process, the outcome is employed to take many academic and administrative decisions. 
Like any new introduction, this also had its own initial challenges especially regarding effective coordination of the exercise taking place in different centre locations across the country with a lot of attendant impropriety. Today, the University has got over the teething problems associated with the CBT and had indeed gone ahead to deploy this technology in the conduct of its other examinations including university-wide courses with large population of students of 500 and above. Typical of such courses are the General Studies, medical courses, where multiple-choice questions are used for testing, and courses in other disciplines, up to an appropriate academic level the technique is considered suitable for.

Thus, the University of Ilorin has made its mark in this particular regard such that it can boast of using only three centres in Ilorin, Lagos and Minna for its nation-wide post-JAMB screening exercise while the use of CBT for conducting General Studies examinations is today, a common feature. This method, needless to say, represents a great deal of improvement over the former PPT method given the many advantages it came with, which include standardized examination questions, prompt and easy conduct by both the candidates and the concerned staff, elimination of incidence of malpractices, missing results and manipulations.

Other justifications for the change-over from the PPT to CBT methods include quick release of results; generation of databank for admitted and registered students; quiet and comfortable test centres; secured test items; unbiased test administration and scoring; faster decision making; reduction in cases of impersonation and adequate coverage of course syllabus in examination questions. There is no doubt therefore that technology today offers many new opportunities for innovation in educational assessment through rich new assessment tasks and potentially powerful scoring, reporting and real-time feedback mechanisms. One potential limitation for realizing the benefits of computer-based assessment in both instructional assessment and large scale testing comes in designing questions and tasks with which computers can effectively interface (i.e., for scoring and score reporting purposes) while still gathering meaningful measurement evidence.

It is against this backdrop of the huge success recorded by the University of Ilorin in the deployment of CBT for not only its post-JAMB screening exercise but more significantly for some other courses, that this paper represents an advocacy for other universities in Nigeria, that are yet to go in that direction.

\section{Methodology}

This study is a descriptive account of the post-JAMB screening exercise as conducted by the University of Ilorin since 2005, when it started. Structured interview was employed to collect data from the immediate past Director of the CBT Examinations in the University. The interview responses were double-checked by the individual experiences of these authors, who are also participants in the exercise over the years. Issues raised in the Interview Schedule border on the commencement, procedure and challenges involved in the conduct of the exercise as well as suggestions for further improvement. Also, seven out of the nine members of the former post-JAMB screening committee and five former invigilators constituted the study's focus group. This was with a view to strengthening or refuting the responses from the Interview. 


\section{Results}

\section{Research Question 1: What necessitated the change-over to CBT method?}

The CBT was initially designed to offset the many limitations of the PPT method used previously for conducting the post-JAMB screening examinations, prior to 2008. These limitations included tedious procedures, delay in the release of results, subjective scoring and missing grades, among others.

Research Question 2: What constitutes the planning stage of the CBT Examination at inception?

At the inception of the post-JAMB CBT screening exercise, a workshop was organized by the University Administration for the senior academic and administrative staff, on how to set objective questions, with the Electronic Testing Company (eTC) - the provider of the CBT delivery-in attendance. The question bank generated had one million questions, authored outside the country. Two well-equipped test centres were provided at Ilorin and Lagos, having two and four halls, respectively. On the part of the candidates, registration was done with the purchase of a reloadable card by e-transact company. From the e-transact site, the card allowed access to the University site to generate the screening code number to access the eTC site for the examination schedule -date, time and venue. There were eight slots per day at one and half hour intervals, starting from 8:30am., and candidates were to arrive one hour before the scheduled time.

\section{Research Question 3: What is the procedure for the administration of the examination using the CBT method?}

After being checked in into a lecture hall, the procedures for the test were demonstrated to the candidates after their computerized index fingerprints and photographs were taken. Three technical men and five invigilators were attached to each hall. The technical men were to assist candidates to $\log$ on to the computer and correct any computer malfunctioning, while the invigilators were to give incidence reports on the examination. Each test consisted of 50-numbered questions in multiple choice formats. Responses in form of letters A to D were entered into the computer by clicking the responses, with opportunity to skip questions and answer them later, and review responses by clicking next or previous. To end the test, finish icon will be clicked, after which the candidates are barred from regaining entry.

\section{Research Question 4: What constitutes the post testing stage of the CBT method?}

Automated scoring of the responses was done. The release of test scores into the e-mail boxes of candidates was purposely delayed for a day or two to forestall commotions that could occur at the test centres in the event of failed scores. The cut-off mark for admission into all University programmes is $50 \%$ while the normal grading of $40 \%$ as minimum pass mark (E) to $70 \%$ and above (A) applies to undergraduate courses. At this early stage, the CBT was under the office of Deputy Vice-chancellor (Academics). Later, a committee was set up known as Committee on Development and Management of CBT, comprising a chairman and members from Educational Measurement and Evaluation, Educational Technology, Science Education, Engineering, University Examination Chairman and a Secretary from Communication Information Technology Centre. 
Research Question 5: In what other areas has the CBT method been deployed by the University?

From 2009, the use of CBT was extended to some undergraduate courses of the University, made compulsory for core courses. These include the General Studies (GNS) courses involving 500 students and above and eligible to others, provided questions are set and submitted. On the average, 88 courses have their examinations conducted through CBT method per session, a situation, which necessitated the need for infrastructural expansion. Systems, which were initially wire-less were later wired to a server and were connected intranet to prevent hacking into the questions. In addition, authored questions by course lecturers are uploaded just before the examination (an hour or less to the examination), to prevent leakages.

\section{Research Question 6: What facilities for the CBT have been expanded by the University?}

Initially, there were two CBT halls accommodating 250 computer systems each, built by the eTC on the basis of Build - Operate- and- Transfer (BOT) arrangement. The joint partnership was for ten years on 75:25 ratio by the eTC and University of Ilorin, respectively. So, starting in 2009, four additional CBT rooms built by the University and equipped with systems by eTC were completed in 2010. Each room accommodates 250 computer systems. So, theoretically, a total of 1,500 computer systems are available for use each time. But considering system breakdown and non-allocation of candidates to cubicles where there are joint (one joint per row of 50 seats totaling five joints per CBT room), on the average only 1,420 systems are functioning for each batch of examination.

Each student pays $\$ 500$ per semester for examination. For instance, over 19,000 students paid post-JAMB screening fee in the second semester of 2010/2011 session totaling 9.5 million. Also, for the 2011/2012 set, about 38,000 candidates took the examination, generating about N19 million. Currently in the joint partnership, the sharing formula is 40:40:20 for the University, eTC and systems maintenance respectively. However, the $20 \%$ for maintenance is given to eTC that carries out all the necessary maintenance activities.

Research Question 7: What constitutes the modular planning of the CBT Examination in the University?

There are various modules developed for CBT called Q-packs; which include among others, Objective Questions, Fill in the Gaps, Essay and Drawing (for Engineering and Mathematics) modules. The commonest module in use is the Objective Questions. For any of the modules, the questions are grouped such that each area of the course content was covered by the lecturer(s) concerned. Questions from different groups can be weighted differently (given different scores). Moreover, negative marking is allowed; a situation that is more applicable to medical programmes.

\section{Research Question 8: What problems militate against the full deployment of the CBT method in} the University?

1. When the systems were wireless, students could cause disruptions in the conduct of examinations by deliberately or otherwise, tampering with the modems.

2. Initially, more than one login was allowed.

3. Matriculation numbers and password of candidates could be given to 
emissaries resulting in impersonation.

4. Too many things on the server slowing down records and requiring formatting and reloading.

5. System malfunctioning occasioned by bad temperature condition at the centres.

6. Insufficient time allocation, especially in numerical courses requiring calculations.

\section{Research Question 9: What was done to overcome these problems?}

1. With the change from the use of modem, each system is wired to the server.

2. With the improved security checks on the systems, candidates cannot access the system for a course more than once.

3. Photographs displayed on the system after login is checked against the student's ID card hung on the neck and turned to the back.

4. Electricity is constantly supplied for air-conditioning to keep the systems under the right temperature.

5. With more equipped CBT halls and well-spaced examination time-tables, adequate time is allocated for all courses.

\section{Discussion of the Findings}

The planning, implementation and monitoring stages in the use of CBT to conduct the post-JAMB screening examinations at the University of Ilorin has been successful due to some factors. These factors include the ICT policy orientation of the University Administration and the Public-Private-Partnership technique used in involving an ICT provider (JKK). Such partnership has made possible the provision of adequately conducive testing environment in terms of buildings and other ICT infrastructure, which according to Trotter (2001), are compulsory for any successful ICT-driven exercise and programme.

The benefits to using CBT for examinations are enormous. The objectivity and security of the testing and the test items are important steps to eliminating examination malpractices, and improving admission and examination processes in the university system. These benefits have been corroborated by Blurton (2002), who opined that with the use of ICTs, universities can improve the admission process by putting admission forms on-line and receiving completed forms online. They can also generate cards for entrance qualifying and semester examinations online. These procedures would speed up admission and examination processes and help in faster results' declaration. Another benefit of CBT is the use of archival databank for the eventually admitted candidates.

The study also revealed the problems encountered during the 2008 University of Ilorin CBT-driven screening exercise as ranging from network problems, erratic power supply to inadequate skills in computer use by candidates. These problems bothering on inadequate capacity of Nigerian universities to lead the process of integrating ICT in education have been linked to lack of access to infrastructure, affordable and sufficient bandwidth and the human resource capacity to exploit the technology. Hence, Nigerian and indeed, African universities are lagging behind in the global ICT context except the University of South Africa and most of those in North Africa, where they have well-developed international relationships along with access to high-speed connectivity (Farrel and Isaacs, 2007). 
This study's findings were similar to those of Scalise. \& Gifford (2006) and Tella and Bashorun (2012) regarding some constraints to effective ICT operations in education, which include lack of access to ICT infrastructure, affordable connectivity with sufficient band width, and a reliable supply of electricity. However, inadequate infrastructure has been handled well by the PPP arrangement embarked upon by the University of Ilorin CBT project.

Another crucial deficiency in the CBT design is non-provision for disabled candidates. Thompon, Thurlow Quenemoen, and Lehr (2002) observed that most states and testing companies have not specifically considered the needs of students with disabilities in the design of CBT. In a survey on computer use by students with disabilities in Germany, Ommerbon and Schuemer (2001) found the cost of acquiring and using a computer the greatest barrier, seconded by a lack of training opportunities. As stated by Bowe (2000), if a product or service is not useable by some individuals, it is the responsibility of its developers, to find ways to make it useable, or at minimum, to arrange for it to be used together with assistive technologies of the users' choice. One potential limitation for realizing the benefits of CBT in both instructional assessment and large scale testing comes in designing questions and tasks with which computers can effectively interface (i.e., for scoring and score reporting purposes) while still gathering meaningful measurement evidence (Scalise \& Gifford, 2006).

\section{Conclusion}

In spite of the giant strides of the University of Ilorin in deploying the CBT method for the conduct of both the pre-JAMB and other general examinations of the University, there would still be room for further improvement so as to sharpen further, the few rough edges being experienced presently. It is however, in furtherance of the advocacy for other Nigerian universities that certain recommendations are made.

\section{Recommendations}

1. Any form of ICT development is capital-intensive. The initial expenses of CBT adoption include central hardware (internet), local telecommunications hardware, machines in schools and test authoring and delivery software, among others. Other Nigerian universities should learn from the University of Ilorin by involving private organizations as partners in progress to finance CBT in education.

2. For a successful ICT-driven educational process, there must be a properly focused and consistent ICT policy orientation to support building of pervasive ICT infrastructure, focused capacity building in human resources, as well as favourable enabling legal, regulatory and policy environments. To this end, staff and students in these universities need adequate competencies in computer skills as a basis for using CBT for semester examinations.

3. Generally, the government policy on computer education at the primary and secondary school levels should be reinforced to make all students computer-literate. This will prevent computer literacy being part of the examination, instead of being a tool for its conduct.

4. Innovations can happen and be sustained only when those who will be affected by it, directly/indirectly, know exactly why such an innovation is being introduced, what the 
implications are on their lives, and what part they can play in ensuring its success. Since CBT is to serve the university communities, wide consultation and mobilization processes are necessary to develop a sense of ownership and sustainability.

5. To take care of disabled candidates, CBTs need to be accessible for a variety of forms of assistive technology such as key guards, specialized keyboards, trackballs, screen readers and screen enlargers.

6. Computers, for one reason or another, tend to break down or are prone to random faults. Therefore, candidates using CBT must have a backup system in place. All work must be saved to a removable drive to facilitate the transfer of the examination paper to the backup, if need be. 


\section{References}

America Psychological Association. (1986). Guidelines for computer-based tests and interpretations. Washington, DC: American Psychological Association.

Blurton, C. (2002). New directions of ICT use in education. Retrieved on November 25 2011, from: http://www.unesco.org/education/educationprog/lwf/al/edict.pdf.

Bowe, F. (2000). University design in education: Teaching non traditional students. Westport, C.T: Bergin and Garvey.

Bugbee, A. C. (1996). The equivalence of paper-and-pencil and computer- based testing. Journal of Research in Computer Education, 28(3), 282-299.

Butler, D. L. (2003). The impact of computer-based testing on student attitudes and behaviour. The Technology Source. Retrieved March 15, 2010, from http:// ts.mivu.org/default.asp?show=article \&id=1034

Donn, J. S. (1991). Effects of computer-based tests on the achievement, anxiety, and attitudes of grade 10 science students. Educational and Psychological Measurement, 51(3), 735-745. doi:10.1177/0013164491513025

Envisage International Cooperation (2010). Computer based test. Retrieved on November 25 2011 , from: http://www.internationalstudents.com/study_usa/application-process/standardized-test s/computer-based-tests.shtml

Farrel, G. \& Isaacs, S. (2007). Survey of ICT and education in Africa. A summary report based on 53 country surveys. Washington, D.C.: infodev/world bank. Retrieved on November 25 2011, from: http://www.infodev.org/en/publication.353.html

Friedrich, S. (2008). Quality features of TC Exam: An open source computer-based assessment software. Towards a research agenda on computer-based assessment. Retrieved on November 25 2011, from: http://www.nremt.org/about/CBT.home.asp.

Harding R. \& Raikes, N. (2000). ICT in assessment and learning: The evolving role of an external examination board.

Jekayinfa, A. A. (2008) "History and Development of Public Examination Bodies for Tertiary Institutions". In Perspectives on the History of Education in Nigeria. Retrieved on March 202012 from: www.unilorin.edu.ng/publications/.../JAMBANDNABTEB.doc.

Kumar, R (2006). Convergence of ICT and Education. World Academy of Science, Engineering and Technology 40 2008. Retrieved on November 25 2011, from: http://www.waset.org/journals/waset/v40/v40-95.pdf

Lynch, E. (1997). Equivalence of computer versus paper-and-pencil academic testing in an introductory psychology course (Doctoral dissertation, Arizona State University). Dissertation Abstracts, 58-03A, 0833.

Marson, B. J., Patry, M., \& Berstein, D. J. (2001). An examination of the equivalence between non-adaptive computer-based and traditional testing. Journal of Educational Computing Research, 24(1), 29-39. doi:10.2190/9EPM-B14R-XQWTWVNL

Mazzeo, J., \& Harvey, A. L. (1988). The equivalence of scores from automated and 
conventional educational and psychological tests. New York, NY: College Entrance Examination Board.

National Governors Association (2002). Using electronic assessment to measure student performance. Education Policy Studies Division: National Governors Association.

Olsen, J. B., Maynes, D. D., Slawson, D., \& Ho, K. (1986). Comparison and equating of paper-administered, computer-administered and computerized adaptive tests of achievement. Paper presented at the Annual Meeting of the America Education Research Association, San Francisco, CA.

Ommerbon, R. \& Schuemer, R. (2001). Using computers in distance study: Results of a survey amongst disabled distance students. Retrieved on November 25 2011, from: http://www.fernuni-hagen.de/ziff._

Ricketts, C., \& Wilks, S. J. (2002). Improving student performance through computer-based assessment: insights from recent research. Assessment \& Evaluation in Higher Education, 27(5), 475-479. doi:10.1080/0260293022000009348International.

Scalise, K. \& Gifford, B. (2006). Computer-Based Assessment in E-Learning: A Framework for Constructing "Intermediate Constraint" Questions and Tasks for Technology Platforms. Journal of Technology, Learning, and Assessment, 4(6). Retrieved on March 142012 from http://www.jtla.org

Thompson, S.J., Thurlow, M.L., Quenemoen, R.F. \& Lehr, C.A. (2002). Access to computer-based testing for students with disabilities (synthesis report 45). Minneapolis, M.N: University of Minnesota, National Centre on Educational Outcomes.

Trotter, A. (2001). Testing computerized exam. Education week, 20 (37), 30-35. Retrieved on November 252011 from: http://www.edweek.org/ew/ewstory.cmf?slug=37online.h20,

Schenkman, B., Fukuda, T., \& Persson, B. (1999). Glare from monitors measured with subjective scales and eye movements. Displays, 20, 11-21. doi:10.1016/S01419382(98)00055-9

Wikipedia: The Free Encyclopedia (2012). Computer-based assessment. Retrieved on November 252011 from : http://en.wikipedia.org/wiki/Computer-based_assessment

Wingenbach, G. J. (2000). Agriculture students' computer skills and electronic exams. Journal of Agricultural Education, 41(1), 69-78. doi:10.5032/ jae.2000.01069 